\title{
Treatment-related toxicity and symptom-related bother following postoperative radiotherapy for prostate cancer
}

\author{
Michael Sia, MSc, MD; George Rodrigues, MSc, MD; ${ }^{\dagger}$ Cynthia Menard, MD; ${ }^{*}$ Andrew Bayley, MD; ${ }^{*}$ Robert \\ Bristow, MD, PhD; ${ }^{*}$ Peter Chung, MBBCh, ${ }^{*}$ Mary Gospodarowicz, FRCPC, FRCR, MD; ${ }^{*}$ Michael Milosevic, \\ $M D ;{ }^{*}$ Padraig Warde, MBBCh; ${ }^{*}$ Charles Catton, MD, FRCPC
}

See related article on page 112.

Can Urol Assoc J 2010;4(2):105-11

\section{Abstract}

Introduction: Patients have reported late effects and symptom-related bother following postoperative radiotherapy for prostate cancer. Methods: Patients treated with postoperative radiotherapy were surveyed at a median 56 months after radiotherapy using the Prostate Cancer Radiation Therapy instrument. A retrospective review was undertaken to obtain Radiation Therapy Oncology Group-Late Effects Normal Tissue (RTOG-LENT) toxicity scores at baseline and during follow-up.

Results: Survey response was $64.5 \%$. Median prostate bed radiation dose was 66 Gy given at a median 14 months after surgery. Adjuvant hormone therapy was given for 2 to 3 years to 40 patients; 22 received salvage therapy.

PCRT impairment subscales were reported as mild for gastrointestinal dysfunction, moderate for genitourinary dysfunction and marked for sexual dysfunction. The use of one or more incontinence pads daily was reported by $25.6 \%$ and was similar to $23 \%$ use reported at baseline. Frequent or worse urinary frequency or hematuria was reported by $4.8 \%$, and by $8.4 \%$ of respondents for bowel dysfunction. Moderate to severe disruption from bowel and bladder dysfunction was reported by up to $5.4 \%$ and $2.4 \%$ of respondents, respectively.

Erectile function was described as poor to none in $88.3 \%$ of respondents, and dissatisfaction with sexual functioning was reported by $42.7 \%$. Counselling or treatment was offered to $59 \%$ of those followed.

Conclusion: Combined surgery and postoperative radiotherapy are associated with low and moderate rates of bowel and bladder dysfunction respectively, with low reported bother. High levels of sexual dysfunction and bother are seen following combined therapy. More effective pre- and post-treatment counselling are required, along with research into more effective prevention and treatment strategies.

\section{Résumé}

Introduction : Des patients ont signalé l'apparition d'effets tardifs et de symptômes incommodants après une radiothérapie postopératoire pour le traitement d'un cancer de la prostate.
Méthodologie : On a mené un sondage auprès de patients traités par radiothérapie postopératoire environ 56 mois (valeur médiane) après cette thérapie à l'aide du questionnaire de qualité de vie liée à une radiothérapie pour traiter un cancer de la prostate (QdVPCRT). Une analyse rétrospective a ensuite été menée à l'aide du questionnaire du RTOG (Radiation Therapy Oncology Group) sur les effets tardifs sur le tissu normal pour obtenir les scores de toxicité au départ et pendant le suivi.

Résultats : Le taux de réponse au sondage était de 64,5\%. La dose médiane de rayonnement au niveau de la région prostatique était de 66 Gy administrée environ 14 mois (valeur médiane) après I'intervention chirurgicale. Quarante patients ont reçu une hormonothérapie adjuvante pendant 2 à 3 ans; 22 patients ont reçu un traitement de sauvetage.

Les sous-échelles de symptômes du questionnaire QdV-PCRT ont montré un léger taux de troubles gastro-intestinaux, un taux modéré de troubles génito-urinaires et un taux prononcé de troubles sexuels. Le recours à une ou plusieurs serviettes pour incontinents par jour a été signalé par $25,6 \%$ des patients, soit un taux similaire au taux de $23 \%$ signalé au départ. Une miction fréquente ou accrue ou une hématurie ont été signalées par 4,8 \% des patients, et par $8,4 \%$ des répondants ayant signalé des troubles intestinaux. Des troubles intestinaux et vésicaux modérés ou graves ont été signalés par un maximum de $5,4 \%$ et $2,4 \%$ des patients, respectivement.

La fonction érectile a été décrite comme étant faible ou nulle chez $88,3 \%$ des patients, et le taux signalé d'insatisfaction quant à la fonction sexuelle était de $42,7 \%$. Des conseils ou un traitement ont été offerts à $59 \%$ des patients suivis.

Conclusion : L'association d'une intervention chirurgicale et d'une radiothérapie postopératoire est liée à des taux faibles et modérés de troubles intestinaux et vésicaux, respectivement, et un faible taux de symptômes incommodants. Des taux élevés de troubles et symptômes incommodants sur le plan sexuel sont observés après le traitement. Un counseling plus efficace avant et après le traitement est nécessaire, de même que des études visant l'élaboration de meilleures stratégies de prévention et de traitement.

\section{Introduction}

Three randomized trials have demonstrated the efficacy of immediate postoperative radiotherapy to the prostate bed compared to observation alone for those with high-risk patho- 
logical features. These improved outcomes for immediate treatment include survival and metastases-free survival, ${ }^{1}$ biochemical relapse-free survival ${ }^{2-4}$ and local control. ${ }^{2,3}$ Similarly, pooled retrospective data for 1540 patients treated for a prostate-specific antigen (PSA) defined recurrence have shown that salvage radiotherapy can result in long-term biochemical relapse-free survival, with the greatest advantage shown for men with a postoperative PSA of less than or equal to $0.5 \mathrm{ng} / \mathrm{L}$, positive margins and a long PSA doubling time. ${ }^{5}$

Taken together, these data show a clear benefit with postoperative radiotherapy for those exhibiting adverse postoperative pathology or PSA kinetics, although the optimal timing of radiotherapy remains to be determined. The question of whether radiotherapy is best given postoperatively to all at-risk men or selectively to those with evidence of postoperative biochemical progression is unanswered and is being addressed by the ongoing National Cancer Institute of Canada-Clinical Trial Group/Medical Research Council (NCIC-CTG/MRC) PR-13 trial. ${ }^{6}$ In the absence of data, the decision to treat or to wait must be made with the patient and take into account the risks and benefits of each approach.

Data from 3 randomized trials, a pooled series and single centre experiences all show an adverse long-term effect of combined treatment on gastrointestinal (GI) and genitourinary (GU) function. 3,4,7-11 These 3 trials demonstrate that overall GI and GU toxicity ${ }^{3,4}$ or GI and GU complications ${ }^{7}$ are significantly worse for those randomized to surgery and radiotherapy compared to those randomized to surgery alone. However, toxicity grading of treatment may underestimate the true extent of a problem, and may not address the issues that are most important to the patient, so it is important to also evaluate the impact of treatment on quality of life. ${ }^{12}$ The effects of prostate cancer treatment on quality of life have been investigated for surgery, external beam radiotherapy and brachytherapy, ${ }^{12-17}$ but less extensively for combined surgery and radiotherapy.

This study was undertaken to provide a cross-sectional evaluation of a single centre experience with immediate or delayed postoperative radiotherapy for localized prostate cancer. Toxicity and health-related quality of life data were collected at a point where contribution of the late effects from radiotherapy to outcome should be apparent. The goal was to provide insights into the anticipated toxicity of combined treatment and its impact on health-related quality of life. This information may be used to inform patients and physicians considering the use of postoperative prostate radiotherapy, and to guide research on minimizing treatmentrelated toxicity and mitigating its effects on quality of life.

\section{Methods}

The University Health Network Ethics Board approved the study protocol and all subjects consented to participation.
Candidates treated with adjuvant and salvage postoperative radiotherapy for prostate cancer were asked to assess symptoms and associated bother related to bowel, bladder and sexual functioning for the previous 4 weeks using the validated Prostate Cancer Radiation Late Toxicity (PCRT) toxicity and health-related quality of life questionnaire. ${ }^{18}$

Functional impairment scores for each domain were calculated by giving all responses a value of 1 (first response) to 5 (last response), and the final score for each subscale was normalized to a maximum of 100 . A score of 100 denotes that the patient is experiencing no changes in that domain; a score between 75 and 99 denotes very small changes that are not likely to be clinically relevant. A score between 50 and 75 denotes relatively small, but clinically relevant changes, and a score between 25 and 50 denotes moderate changes. A score between 0 and 24 denotes severe changes in that domain.

Subscales with missing data was not calculated for incomplete responses, and symptoms or bother addressed by each question were analyzed and summarized independently.

Bladder, rectal and sexual function recorded at the time of referral for radiotherapy and at each follow-up visit were extracted from the medical record, and questionnaire responders and nonresponders were identified and recorded separately. Bladder and rectal function were scored using the Radiotherapy Oncology Group Late Effects Normal Tissue (RTOG-LENT) criteria. ${ }^{19}$ Erectile function summarized from the medical record was recorded as either none, insufficient for intercourse or adequate for intercourse.

\section{Postoperative treatment}

The median prescribed radiation dose was 66 Gy (range 58 Gy to 73.98 Gy). Most patients (161/171) were treated to the prostate bed alone; 10 received pelvic nodal and prostate bed radiotherapy. The 4-field box was the most commonly employed treatment technique; only 2 patients were treated with a 3- or 6-field technique. Twenty-seven patients received additional radiation to the urethrovesicle anasatamosis. Adjuvant hormone therapy of 2 to 3 years duration was given to 40 patients $(23.3 \%)$. Salvage hormone therapy was administered to 22 patients for biochemical failure following postoperative therapy.

The effect of adjuvant hormone therapy on long-term sexual function was investigated by comparing PCRT scores in the sexual domain (questions 24 to 28 ) between those patients who did and did not receive 2 to 3 years of adjuvant hormone therapy. Potential differences were evaluated with a non-parametric two-sample Wilcoxon tests for each question. 


\begin{tabular}{lc}
\hline $\begin{array}{l}\text { Table 1. Patient characteristics for } 171 \\
\text { postoperative radiotherapy for prostate cancer }\end{array}$ \\
\hline Median age at survey & 69.8 (range 53-81) \\
\hline Pathological staging & Number (\%) \\
\hline pT2 & $60(35.1)$ \\
pT3a & $56(32.7)$ \\
pT3b & $40(23.4)$ \\
pT4 & $2(1.2)$ \\
pTX/not recorded & $13(7.6)$ \\
N0 & $95(55.6)$ \\
N1 & $2(1.2)$ \\
NX/not recorded & $74(43.1)$ \\
\hline Surgical Gleason score & \\
6 or less & $29(17.0)$ \\
7 & $101(59.1)$ \\
8 to 10 & $25(14.6)$ \\
Not recorded/assessable & $16(9.3)$ \\
\hline Nerve-sparing surgery & \\
Bilateral & $37(21.6)$ \\
Unilateral & $18(10.5)$ \\
No & $29(19.2)$ \\
Not recorded & $87(57.6)$ \\
\hline Status at radiotherapy & \\
Adjuvant & $43(25.1)$ \\
Salvage & \\
\hline & \\
\hline
\end{tabular}

\section{Results}

The survey response rate was $64.5 \%(171 / 265)$. Median follow-up was 56 months (range 30 to 85 months) from the completion of radiation therapy to posting of the questionnaires. The median time from prostatectomy to the completion of radiotherapy was 14 months (range 2 to 200 months), and median follow-up for toxicity scores was 59 months (range 0 to 106 months) from start of radiotherapy.

The patient characteristics are summarized in Table 1. Physician-assessed baseline functioning is shown in Table 2 , as are post-radiotherapy functioning, toxicity, medical and surgical interventions.

Ten patients (5.8\%) required interventions for bladder complications following combined treatment. Two patients underwent dilation of a urethral stricture, and 1 patient required insertion of an artificial sphincter. Long-term medical intervention for these patients included the use of selective alpha blockers, oxybutynin and imipramine. Eleven patients (6.4\%) required interventions for $\mathrm{Gl}$ treatment complications following combined therapy. One patient underwent hyperbaric oxygen therapy, with improvement. Long-term medical intervention for these patients included cortisone enemas, 5-aminosalicylic acid suppositories and loperamide.

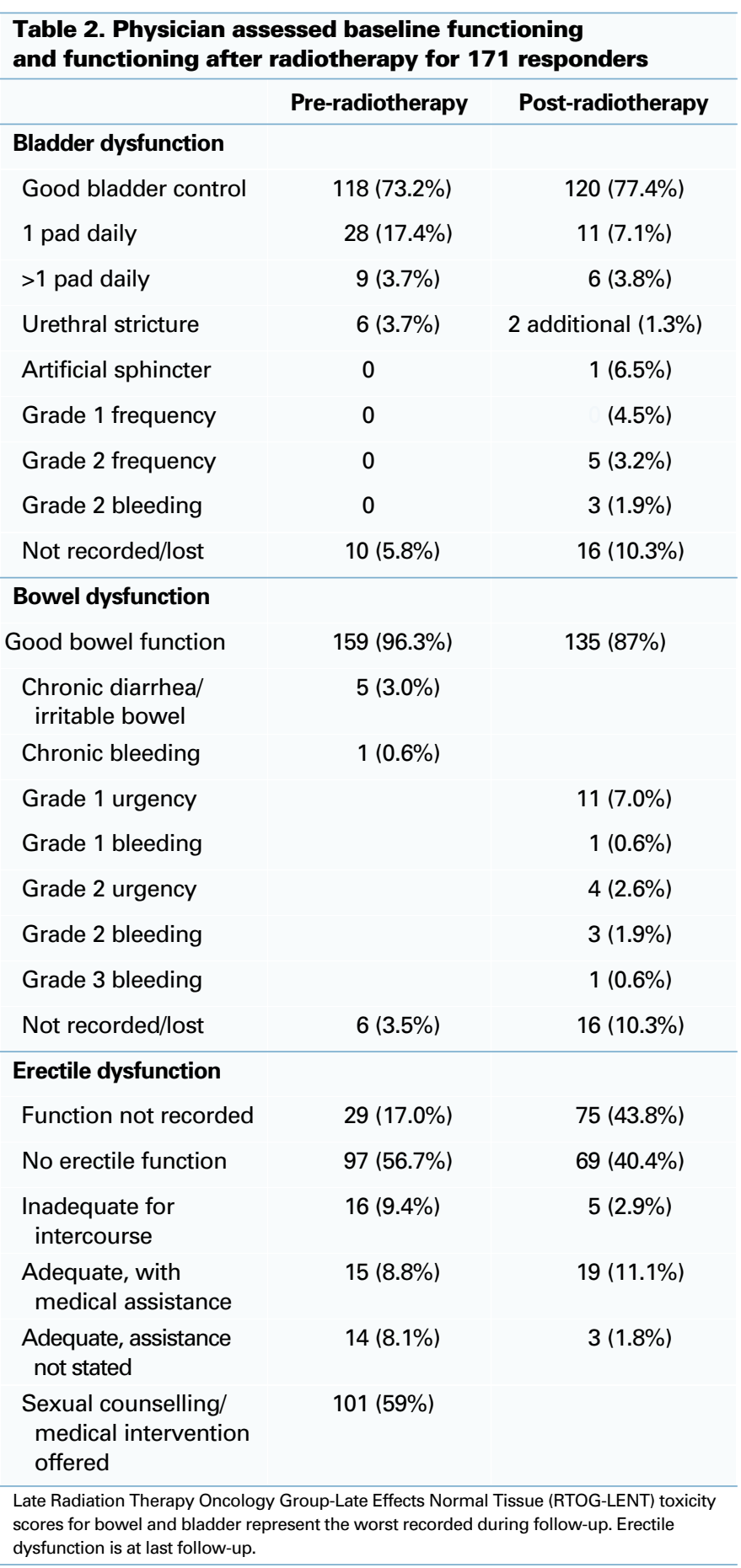

\section{PCRT questionnaire responses}

Overall, the Gl subscale demonstrated mild impairment (mean score 91.75 , range 60.42 to $100 ;$ SD 10.28). The GU subscale demonstrated moderate impairment with large variability (mean score 60.0, range 6.25 to 100; SD 20.34). The sexual scale demonstrated moderate to severe impair- 
Table 3. Responses for the Prostate Cancer Radiation Late Toxicity bowel module, bowel health-related quality of life

\begin{tabular}{|c|c|}
\hline \multicolumn{2}{|l|}{ Rectal bleeding } \\
\hline \multicolumn{2}{|l|}{ Frequency } \\
\hline Never & $82.5 \%$ \\
\hline Any degree & $17.5 \%$ \\
\hline Sometimes & $14.5 \%$ \\
\hline Frequently & $1.8 \%$ \\
\hline Most of the time & $0 \%$ \\
\hline All or almost all of the time & $1.2 \%$ \\
\hline \multicolumn{2}{|l|}{ Amount of bleeding } \\
\hline None & $82.6 \%$ \\
\hline Any degree & $17.4 \%$ \\
\hline Slight tinge & $7.8 \%$ \\
\hline Light & $9.0 \%$ \\
\hline Medium & $0.6 \%$ \\
\hline Heavy & $0 \%$ \\
\hline \multicolumn{2}{|l|}{ Upset or disruption } \\
\hline None & $94.6 \%$ \\
\hline Very little & $3.6 \%$ \\
\hline Small & $1.8 \%$ \\
\hline Moderate & $0 \%$ \\
\hline Severe & $0 \%$ \\
\hline \multicolumn{2}{|l|}{ Liquid or loose bowel movement } \\
\hline None (or constipated) & $59.8 \%$ \\
\hline Any degree & $40.2 \%$ \\
\hline Less than $1 /$ day & $21.6 \%$ \\
\hline $1 /$ day & $10.2 \%$ \\
\hline 2-4/day & $6.6 \%$ \\
\hline 5 or more/day & $1.8 \%$ \\
\hline \multicolumn{2}{|l|}{ Upset or disruption } \\
\hline None & $75.9 \%$ \\
\hline Very little & $13.3 \%$ \\
\hline Small & $6.6 \%$ \\
\hline Moderate & $3.6 \%$ \\
\hline Severe & $0.6 \%$ \\
\hline \multicolumn{2}{|l|}{ Pelvic pain or cramping } \\
\hline \multicolumn{2}{|l|}{ Frequency } \\
\hline Never & $78.6 \%$ \\
\hline Any degree & $21.4 \%$ \\
\hline Sometimes & $19.0 \%$ \\
\hline Frequently & $1.8 \%$ \\
\hline Most of the time & $0 \%$ \\
\hline All or almost all of the time & $0.6 \%$ \\
\hline \multicolumn{2}{|l|}{ Severity of discomfort } \\
\hline None & $82.2 \%$ \\
\hline Any degree & $17.8 \%$ \\
\hline Mild & $10.7 \%$ \\
\hline Somewhat & $3.6 \%$ \\
\hline Moderate & $2.4 \%$ \\
\hline Very & $1.2 \%$ \\
\hline
\end{tabular}

ment (mean score 33.67, range 0 to 100; SD 21.71). Responses for functioning and bother are summarized in Table 3, Table 4 and Table 5. There was no statistically significant difference identified between each of the sexual domain scores (questions 24 to 28) for those who received 2 to 3 years of adjuvant hormone therapy in addition to radiotherapy.

\begin{tabular}{lc}
\hline Rectal urgency & \\
Never & $60.5 \%$ \\
Any degree & $39.5 \%$ \\
Rarely & $33.5 \%$ \\
Frequently & $4.2 \%$ \\
Most of the time & $1.2 \%$ \\
All or almost all of the time & $0.6 \%$ \\
Upset or disruption & \\
None & $74.3 \%$ \\
Very little & $19.8 \%$ \\
Small & $3.6 \%$ \\
Moderate & $2.4 \%$ \\
Severe & $0 \%$ \\
\hline Loss of bowel control & \\
Total control & $65.3 \%$ \\
Any loss of control & $34.7 \%$ \\
Control most of the time & $29.3 \%$ \\
Some control & $3.6 \%$ \\
Very little control & $1.8 \%$ \\
No control & $0 \%$ \\
Upset or disruption & \\
None & $70.5 \%$ \\
Very little & $19.3 \%$ \\
Small & $4.8 \%$ \\
Moderate & $4.8 \%$ \\
Severe & $0.6 \%$ \\
\hline Each respondent did not answer every question. & \\
\hline
\end{tabular}

\section{Discussion}

The toxicity profiles of surgery and external beam radiotherapy differ with respect to symptoms, time to onset and to a lesser degree, the target organs. The toxicity of combined treatment is worse than for surgery alone in 3 randomized trials. ${ }^{2-4}$ The reported toxicity data from retrospective series are mostly from small institutional series, ${ }^{10}$ however Feng and colleagues ${ }^{8}$ reported the combined late effects for a pooled retrospective series of 959 men who received adjuvant or salvage postoperative radiotherapy.

Toxicity profiles and treatment toxicity grading are limited in that they generally are physician-assessed and may underestimate the true extent of a problem, and may not lend adequate weight to side-effects that are most important to the patient. ${ }^{12}$ Erectile dysfunction for example, was not addressed in any of the major reports cited above. Instruments that measure health-related quality of life provide a more comprehensive evaluation of treatment impact on an individual. ${ }^{18,20-23}$ We chose the PCRT validated instrument for this study because it is self-administered and suitable as a mail-in questionnaire. Moreover, the PCRT tool collects information in the Gl, GU and sexual domains and it was specifically developed for patients who have undergone radiotherapy for prostate cancer. The response rate to our questionnaire was $64.5 \%$ and is in keeping with other questionnaire-based studies of prostate cancer treatment outcomes. ${ }^{24-27}$

The impact of combined surgery and radiotherapy on health-related quality of life has not been extensively investigated. The only randomized data is from Moinpour and 
colleagues who undertook a 5-year longitudinal assessment of 217 patients entered into the previously cited Southwest Oncology Group trial. ${ }^{28}$ Global health-related quality of life was worse for the radical prostatectomy-radiotherapy group during radiotherapy ( $40 \%$ normal vs. $56 \%$ normal), however this result had reversed by year 5 , when $69 \%$ in the prostatectomy-radiotherapy group reported normal global functioning versus $51 \%$ for the surgery alone group.

Patients reported statistically significantly worse bowel function through year 2 and worse urinary function throughout the course of the study if they received radiotherapy. Urinary function remained stable for both groups after the acute radiotherapy period, but rectal function deteriorated over time for patients in both treatment groups. Erectile dysfunction was present at baseline for surgery alone and combined treatment in $93 \%$ and $94 \%$, respectively. At year 5 , this improved in both groups to about $80 \%$.

Three non-randomized longitudinal evaluations of combined therapy on heath-related quality of life have been reported. ${ }^{13,29,30} \mathrm{Hu}$ and colleagues demonstrated a greater decrement in bowel and bladder functioning 12 to 18 months after combined therapy compared to surgery alone. ${ }^{13}$ Pearse and colleagues ${ }^{29}$ and Pinkawa and colleagues ${ }^{30}$ only investigated the effects of combined treatment, and concluded that the long-term effects on quality of life were small after the acute radiation period had passed.

The current study provides health-related quality of life information at only one time point, although it is sufficiently remote from treatment that most late radiation effects would have likely appeared. ${ }^{31}$ Unsurprisingly, patient-reported complication rates were higher or more completely reported in all domains than were our physician-assessed complications. This result reinforces the value in evaluating treatment-related toxicity with the PCRT or similar instruments.

As with Moinpour and colleagues, we identified global dysfunctioning to be worst in the sexual domain, moderate in the urinary domain and minor in the bowel domain. ${ }^{28}$

Surprisingly, urinary incontinence of any degree was reported by $60.4 \%$ of respondents, while $26.2 \%$ reported more than 3 episodes of incontinence per day. This was considerably more than was reported at baseline, when $73 \%$ reported good bladder control. It is not known whether this represents a real change over time, or under-reporting at baseline. However, the number of patients actually reporting the use of incontinence pads are similar pre- and postradiotherapy at $23 \%$ and $25.6 \%$, respectively. This suggests that the addition of radiotherapy did not increase the rate of severe urinary incontinence in these patients.

Frequent or worse dysuria and hematuria were not commonly reported by our patients, and occurred in $2.4 \%$ for each symptom, respectively. By comparison, Feng and colleagues ${ }^{8}$ reported $11 \%$ grade 2 and $1 \%$ grade 3 urinary toxicity for combined therapy, although Wiegel and colleagues ${ }^{4}$

\begin{tabular}{lc} 
Table 4. Responses to Prostate Cancer Radiation Late Toxicity \\
bladder module, bladder health-related quality of life \\
\hline Dysuria \\
Never \\
Any degree \\
Sometimes & $84.6 \%$ \\
Frequently & $15.4 \%$ \\
Most of the time & $13 \%$ \\
All or almost all of the time & $1.2 \%$ \\
Upset or disruption & $0.6 \%$ \\
None & $0.6 \%$ \\
Very little & \\
Small & $88.2 \%$ \\
Moderate & $7.1 \%$ \\
Severe & $2.4 \%$ \\
Hematuria & $2.4 \%$ \\
Never & $0 \%$ \\
Any degree & \\
Rarely & \\
Frequently & $92.8 \%$ \\
Most of the time & $7.2 \%$ \\
All or almost all of the time & $4.8 \%$ \\
Upset or disruption & $1.8 \%$ \\
None & $0.6 \%$ \\
Very little & $0 \%$ \\
Small & \\
Moderate & $96.4 \%$ \\
Severe & $1.2 \%$ \\
\hline
\end{tabular}

$\begin{array}{lc}\text { Urinary incontinence } & \\ \text { Frequency } & \\ \text { Never } & 39.6 \% \\ \text { Any degree } & 60.4 \% \\ \text { 1/day } & 22.0 \% \\ \text { 2/day } & 12.2 \% \\ \text { 3-5/day } & 18.3 \% \\ \text { Constantly } & 7.9 \% \\ \text { Use incontinence pads } & \\ \text { None } & 74.4 \% \\ \text { Any number } & 25.6 \% \\ \text { 1/day } & 13.4 \% \\ 2 / \text { day } & 7.3 \% \\ 3-5 / \text { day } & 3.7 \% \\ 6 \text { or more/day } & 1.2 \% \\ \text { Upset or disruption } & 80.0 \% \\ \text { None } & 8.5 \% \\ \text { Very little } & 6.7 \% \\ \text { Small } & 2.4 \% \\ \text { Moderate } & 2.4 \% \\ \text { Severe } & 0 \%\end{array}$

Each respondent did not answer every question.

identified only $2.8 \%$ grade 2 and 3 urinary events in patients who received combined treatment in their randomized trial.

Overall, very few patients in our current series experienced moderate or severe bother from urinary dysfunction. Only $2.4 \%$ reported moderate to severe disruption from incontinence, and another $2.4 \%$ reported moderate to severe disruption from dysuria. It is not clear why there is a disassociation between the reported frequency of incontinence and the consequent disruption. It may represent an accommodation to bladder dysfunction over time, or that 


\begin{tabular}{lr}
\hline \multicolumn{2}{l}{ Table 5. Responses to Prostate Cancer Radiation Late Toxicity } \\
sexual module, sexual health related quality of life \\
\hline Ability to attain and maintain an erection \\
Very good \\
Good & $3.1 \%$ \\
Moderate & $0.6 \%$ \\
Poor & $8.0 \%$ \\
Very poor or none & $14.7 \%$ \\
Level of sexual interest & $73.6 \%$ \\
Very high & \\
High & $6.2 \%$ \\
Moderate & $13.0 \%$ \\
Low & $36.4 \%$ \\
No interest & $29.0 \%$ \\
Satisfaction with sexual functioning & $15.4 \%$ \\
Extremely happy/satisfied & \\
Somewhat happy/satisfied & $2.5 \%$ \\
Neither happy or unhappy & $11.5 \%$ \\
Somewhat unhappy/dissatisfied & $25.5 \%$ \\
Not at all happy/satisfied & $17.8 \%$ \\
Sexual activity & $42.7 \%$ \\
Any sexual intercourse & \\
None due to erectile dysfunction & $14.4 \%$ \\
None due to lack of interest & $60.7 \%$ \\
None due to lack of opportunity & $8.5 \%$ \\
None due to choice & $7.2 \%$ \\
\hline Each respondent did not answer every question. & $9.2 \%$ \\
\hline
\end{tabular}

Each respondent did not answer every question. expectations from treatment were appropriately addressed at the outset, but it remains a question for further investigation.

Symptomatic changes in bowel function were a more common problem, occurring frequently or worse in up to $8.4 \%$ of respondents, with liquid or loose bowel movements being the most common complaint (8.4\%). Associated loss of control was seen in $5.4 \%$. This is higher than the $4.4 \%$ grades 2 and 3 toxicity reported by Feng and colleagues, ${ }^{8}$ and the $1.4 \%$ grade 2 toxicity rate reported by Wiegel and colleagues. ${ }^{4}$ It is also higher than the overall grade 3 toxicity rate of $4.2 \%$ reported by Bolla and colleagues in their randomized trial. ${ }^{3}$ This outcome may reflect patient-assessed toxicity reporting in the current report or the use of a higher radiation dose, or more generous radiation treatment volume to define the prostate bed than is used elsewhere. Moderate to severe disruption from some aspect of bowel dysfunction was reported by up to $5.4 \%$ of respondents, and the most frequent problem was with rectal urgency $(5.0 \%)$ and loss of control $(5.4 \%)$.

Dissatisfaction with sexual function was the most adverse outcome identified in this study, and only $2.5 \%$ reported being extremely happy or satisfied with sexual functioning. Extreme unhappiness was reported by $42.7 \%$, and is consistent with the finding that $55.6 \%$ maintained a moderate to very high the level of sexual interest, but $88.3 \%$ experienced impaired function. This level of impairment is similar to that reported by Moinpour and colleagues ${ }^{28}$ and Pinkawa and colleagues ${ }^{30}$ following combined therapy, which was $80 \%$ and $93 \%$, respectively. The pre-radiotherapy impair- ment rate of $79.5 \%$ in this series is consistent with other reports of sexual dysfunction following surgery alone, although nerve-sparing surgery was not routine in our patients. ${ }^{24,32,33}$

We did not identify any significant differences in PCRT scores for those who received adjuvant hormone therapy in addition to radiotherapy, but the sample size is small. The role of adjuvant hormone therapy in the postoperative setting is unknown, and subject of an ongoing randomized trial. ${ }^{6}$ The evaluation of adjuvant hormone therapy on longterm sexual functioning will be an important endpoint in this trial. Greater use of nerve-sparing procedures in appropriate cases might improve baseline erectile function, but few patients in this series who reported adequate function at baseline retained it with subsequent therapy.

Some patients may benefit from post-radiotherapy sexual counselling and medical intervention, however this was not offered to $41 \%$ of patients being followed by a radiation oncologist in this series. Miller and colleagues have noted a similar pattern of practice amongst radiation oncologists. ${ }^{34}$ Our results also suggest that dissatisfaction may be a consequence of unmet expectations from treatment, and that more effective and realistic pre-treatment counselling is required. These results may be useful in that regard.

Ultimately, investigation into the pathophysiology of combined therapy on erectile dysfunction may lead to effective preventive therapy or more effective medical interventions. ${ }^{35,36}$ Postoperative radiation-related injury to bladder, rectum and erectile function may be mitigated in the future through more precise radiation targeting and radiation delivery. These investigations are ongoing. ${ }^{11,37}$

The limitations of this study include the cross-sectional design that provides health-related quality of life at only one point in time, and the physician-assessed baseline comparison, which likely under-reports the degree of impairment present before radiotherapy, particularly in the GU and sexual domains. It is also possible that responders were biased in outcome reporting compared to nonresponders. It is not possible to determine the effect of any bias that may exist, but the late toxicity scores of the responders and nonresponders suggest that the groups are similar.

While it is valuable to know changes in health-related quality of life over time, this study was designed to provide a clear picture of functioning and bother at a point where late complications from both treatment modalities should be well-established. This information is valuable for counselling patients about treatment, and for providing insights into avenues of research to improve treatment outcomes.

\section{Conclusion}

Combined postoperative surgery and radiotherapy for prostate cancer is associated with low and moderate rates of bowel 
and bladder dysfunction, respectively. Associated bother is low in both domains, although an unexpected and marked dissociation was seen between reported rates of urinary incontinence and urinary bother.

Patients report very high levels of sexual dysfunction and sexual bother following combined therapy. More effective pre- and post-treatment counselling is required, along with research into more effective prevention and treatment strategies.

From the ${ }^{*}$ Department of Radiation Oncology, The Princess Margaret Hospital and University of Toronto, Toronto, ON; 'Departments of Radiation Oncology and Epidemiology and Biostatistics, The London Regional Cancer Centre and the University of Western Ontario, London, ON

\section{Competing interests: None declared.}

This paper has been peer-reviewed.

\section{References}

1. Thompson I, Tangen C, Paradelo J, et al. Adjuvant radiotherapy for pathological T3NOMO prostate cancer significantly reduces metastases and improves survival: Long term followup of a randomized trial. J Urol 2009;181:956-62.

2. Thompson IJ, Tangen C, Paradelo J, et al. Adjuvant radiotherapy for pathologically advanced prostate cancer: a randomized clinical trial. JAMA 2006;296:2329-35.

3. Bolla M, van Poppel H, Collette L, et al. European Organization for Research and Treatment of Cancer. Postoperative radiotherapy after radical prostatectomy: a randomised controlled trial (EORTC trial 22911). Lancet 2005;366:572-8.

4. Wiegel T, Bottke D, Steiner U, et al. Phase III postoperative adjuvant radiotherapy after radical prostatectomy compared with radical prostatectomy alone in $\mathrm{pT} 3$ prostate cancer with postoperative undetectable prostate-specific antigen: ARO 96-02/AUO AP 09/95. J Clin Ocol 2009;27:2924-30.

5. Stephenson A, Scardino $P$, Kattan $M$, et al. Predicting the outcome of salvage radiation therapy for recurrent prostate cancer after radical prostatectomy. J Clin Oncol 2007;25:2035-41.

6. Parker C, Sydes M, Catton C, et al. Radiotherapy and androgen deprivation in combination after local surgery (RADICALS): a new Medical Research Council/National Cancer Institute of Canada phase III trial of adjuvant treatment after radical prostatectomy. BJU Int 2007;99:1376-9.

7. Thompson I, Tangen C, Miller G, et al. Adjuvant radiotherapy for pathologic T3 prostate cancer: Results of a randomized, prospective clinical trial with metastases-free survival endpoint. J Urol 2005;173suppl(4):Abstract1665.

8. Feng $M$, Hanlon A, Pisansky $T$, et al. Predictive factors for late genitourinary and gastrointestinal toxicity in patients with prostate cancer treated with adjuvant or salvage radiotherapy. Int I Radiat Oncol Biol Phys 2007;68:1417-23

9. Choo R, Pearse M, Danjoux C, et al. Analysis of gastrointestinal and genitourinary morbidity of postoperative radiotherapy for pathologic T3 disease or positive surgical margins after radical prostatectomy using national cancer institute expanded common toxicity criteria. Int J Radiat Oncol Biol Phys 2008;72:989-95.

10. Parker C, Warde P, Catton C. Salvage radiotherapy for PSA failure after radical prostatectomy. Radiother Oncol 2001;61:107-16.

11. De Meerleer G, Fonteyne V, Meersschout $S$, et al. Salvage intensity-modulated radiotherapy for rising PSA after radical prostatectomy. Radiother Oncol 2008;89:205-13.

12. Litwin $M$, Hays $R$, Fink $A$, et al. Quality-of-life outcomes in men treated for localized prostate cancer. JAMA 1995;273:129-35.

13. Hu J, Elkin E, Pasta D, et al. Predicting quality of life after radical prostatectomy: results from CaPSURE. J Urol 2004;171 (2 Pt 1):703-7.
14. Litwin $M$, Gore J, Kwan L, et al. Quality of life after surgery, external beam irradiation, or brachytherapy for early-stage prostate cancer. Cancer 2007; 109:2239-47.

15. Davis J, Kuban D, Lynch D, et al. Quality of life after treatment for localized prostate cancer: differences based on treatment modality. J Urol 2001;166:947-52.

16. Sanda M, Dunn R, Michalski J, et al. Quality of life and satisfaction with outcome among prostate-cancer survivors. N Engl J Med 2008;358:1250-61.

17. Lee $W$, Hall M, McQuellon $R$, et al. A prospective quality-of-life study in men with clinically localized prostate carcinoma treated with radical prostatectomy, external beam radiotherapy, or interstitial brachytherapy. Int J Radiat Oncol Biol Phys 2001;51:614-23.

18. Rodrigues $G$, Bauman $G$, Lock $M$, et al. Psychometric properties of a prostate cancer radiation late toxicity questionnaire. Health Qual Life Outcomes 2007;5:29. Available at: http://www.halo.com/content/5/1/29 (Accessed February 24, 2010).

19. Storey $M$, Pollack $A$, Zagars $G$, et al. Complications from radiotherapy dose escalation in prostate cancer: preliminary results of a randomised trial. Int I Radiat Oncol Biol Phys 2000;48:635-42.

20. Wei J, Dunn $R$, Litwin $M$, et al. Development and validation of the expanded prostate cancer index composite (EPIC) for comprehensive assessment of health-related quality of life in men with prostate cancer. Urology 2000;56:899-905.

21. Esper $\mathrm{P}, \mathrm{Mn}_{\mathrm{F}}$, Chodak $\mathrm{G}$, et al. Measuring quality of life in men with prostate cancer using the functional assessment of cancer therapy-prostate instrument. Urology 1997;50:920-8.

22. Potosky A, Harlan L, Stanford J, et al. Prostate cancer practice patterns and quality of life: the Prostate Cancer Outcomes Study. J Natl Cancer Inst 1999;91:1719-24.

23. Borghede G, Sullivan M. Measurement of quality of life in localized prostatic cancer patients treated with radiotherapy. Development of a prostate cancer-specific module supplementing the EORTC QLQC30. Qual Life Res 1996;5:212-22.

24. Shrader-Bogen C, Kiellberg J, McPherson C, et al. Quality of life and treatment outcomes: prostate carcinoma patients' perspectives after prostatectomy or radiation therapy. Cancer 1997;79:1977-86.

25. Crook J, Esche B, Futter N. Effect of pelvic radiotherapy for prostate cancer on bowel, bladder, and sexual function: the patient's perspective. Urology 1996;47:317-94.

26. Skala M, Rosewall T, Dawson L, et al. Patient-assessed late toxicity rates and principal component analysis after image-guided radiation therapy for prostate cancer. Int I Radiat Oncol Biol Phys 2007;68:690-8.

27. Nichol A, Chung P, Lockwood G, et al. A phase II study of localized prostate cancer treated to $75.6 \mathrm{~Gy}$ with 3D conformal radiotherapy. Radiother Oncol 2005;76:11-7.

28. Moinpour C, Hayden K, Unger J, et al. Southwest Oncology Group. Health-related quality of life results in pathologic stage C prostate cancer from a Southwest Oncology Group trial comparing radical prostatectomy alone with radical prostatectomy plus radiation therapy. J Clin Ocol 2008;26:112-20.

29. Pearse M, Choo R, Danjoux C, et al. Prospective assessment of gastrointestinal and genitourinary toxicity of salvage radiotherapy for patients with prostate-specific antigen relapse or local recurrence after radical prostatectomy. Int J Radiat Oncol Biol Phys 2008;72:792-8.

30. Pinkawa M, Fischedick K, Asadpour B, et al. Health-related quality of life after adjuvant and salvage postoperative radiotherapy for prostate cancer - a prospective analysis. Radiother Oncol 2008;88:135-9.

31. Peeters $S$, Heemsbergen $W$, van Putten $W$, et al. Acute and late complications after radiotherapy for prostate cancer: results of a multicenter randomized trial comparing 68 Gy to $78 \mathrm{~Gy}$. Int J Radiat Oncol Biol Phys 2005;61:1019-34.

32. Litwin $M$, Flanders $S$, Pasta $D$, et al. Sexual function and bother after radical prostatectomy or radiation for prostate cancer: multivariate quality-of-life analysis from CaPSURE. Cancer of the Prostate Strategic Urologic Research Endeavor. Urology 1999;54:503-8.

33. Penson D, Mclerran D, Feng Z, et al. 5-year urinary and sexual outcomes after radical prostatectomy: results from the Prostate Cancer Outcomes Study. J Urol 2008;179(5 Suppl):S40-4.

34. Miller $D$, Wei J, Dunn $R$, et al. Use of medications or devices for erectile dysfunction among long-term prostate cancer treatment survivors: potential influence of sexual motivation and/or indifference. Urology 2006;68:166-71.

35. Mulhall J, Morgentaler A. Penile rehabilitation should become the norm for radical prostatectomy patients. J Sex Med 2007;4:538-43

36. Mulhall J, Slovick R, Hotaling J, et al. Erectile dysfunction after radical prostatectomy: hemodynamic profiles and their correlation with the recovery of erectile function. J Urol 2002;167:1371-5.

37. Wiltshire K, Brock K, Haider $M$, et al. Anatomic boundaries of the clinical target volume (prostate bed) after radical prostatectomy. Int J Radiat Oncol Biol Phys 2007;69:1090-9.

Correspondence: Dr. Charles Catton, 610 University Ave., Toronto, ON M5G 2M9; charles.catton@rmp.uhn.on.ca 